\title{
Dynamic Culture of Osteogenic Cells in Biomimetically Coated Poly(Caprolactone) Nanofibre Mesh Constructs
}

\author{
Jose V. Araujo, M.Sc., ${ }^{1-3}$ Cassilda Cunha-Reis, B.Sc., ${ }^{3}$ Tommaso Rada, B.Sc., ${ }^{1,2}$ Marta Alves da Silva, M.Sc., ${ }^{1,2}$ \\ Manuela E. Gomes, Ph.D., ${ }^{1,2}$ Ying Yang, Ph.D., ${ }^{3}$ Nureddin Ashammakhi, M.D., ${ }^{3}$ Rui L. Reis, Ph.D., ${ }^{1,2}$ \\ Alicia J. El-Haj, Ph.D., ${ }^{3}$ and Nuno M. Neves, Ph.D.,
}

In our previous work, biomimetic calcium phosphate-coated poly(caprolactone) nanofibre meshes (BCP-NMs) were demonstrated to be more effective for supporting cell attachment and proliferation under static conditions, when compared with poly(caprolactone) nanofibre meshes (PCL-NMs). In many applications, in vitro cultivation of constructs using bioreactors that support efficient nutrition of cells has appeared as an important step toward the development of functional grafts. This work aimed at studying the effects of dynamic culture conditions and biomimetic coating on bone cells grown on the nanofibre meshes. BCP-NM and PCL-NM were seeded with osteoblast-like cells (MG63-human osteosarcoma-derived cell line). The cell-seeded constructs were cultured within a rotating bioreactor that simulated microgravity, at a fixed rotating speed, for different time periods, and then characterized. Cell morphology, viability, and phenotype were assessed. PCL-NM constructs presented a higher number of dead cells than BCP-NM constructs. Under dynamic conditions, the production of proteins associated with the extracellular matrix of bone was higher on BCP-NM constructs than in the PCL-NM ones, which indicates that coated samples may provide cells with a better environment for tissue growth. It is suggested that improved mass transfer in the bioreactor in combination with the appropriate substrate were decisive factors for this highly positive outcome for generating bone.

\section{Introduction}

E LECTROSPUN NANOFIBRE MESHES have found several applications in many different areas, including tissue engineering. ${ }^{1,2}$ These structures are able to mimic the extracellular matrix (ECM) of tissues, such as bone, thus acting as a favorable substrate to more accurately assess cellular behavior. ${ }^{3}$ For instance, bone is mainly composed of hydroxyapatite nanocrystals dispersed along type I collagen nanofibres. ${ }^{4-7}$ Recently, our group has succeeded in the production of a biomimetic coated poly(calcium phosphatecaprolactone) nanofibre meshes (BCP-NM) structure, which adequately reproduced the structure of the natural ECM of bone in terms of its architecture and composition. 8,9 Poly $(\varepsilon-$ caprolactone) was selected due its biocompatibility and biodegradability. In fact, poly( $\varepsilon$-caprolactone) is degraded by hydrolysis of its ester linkages in physiological conditions. ${ }^{8}$ The choice of poly( $\varepsilon$-caprolactone) was also related to the fact that the material is currently used in the clinic, what may facilitate the translation of the research results into clinical products. In addition, we have shown previously that the surface of poly( $\varepsilon$-caprolactone) nanofibre meshes can be optimized for various cell types through surface modification processes. ${ }^{10}$ The procedure to obtain BCP-NM was already optimized and is described in detail in a previous publication. ${ }^{8}$ It is important to note that the biomimetic coating is intended to provide bone-bonding ability and unlike other strategies involving combinations of polymers with ceramics was not expected to reinforce mechanically the structure. Thus, the effect of the CaP biomimetic coating over the mechanical properties was not tested herein. Information about the mechanical properties of poly( $\varepsilon$-caprolactone) nanofibre meshes can be found in recent publications from our group. ${ }^{11-13}$

We recently reported that BCP-NM was more effective for supporting the attachment and proliferation of osteogenic cells for longer periods of time under static conditions, when compared with the poly(caprolactone) nanofibre mesh (PCLNM) without coating. ${ }^{8}$ However, a more elaborate approach closely mimicking the in vivo environment is required. Thus, dynamic culture conditions are herein explored.

For the dynamic cell culture studies, the technologies most commonly used include the utilization of bioreactors. ${ }^{14-16}$

\footnotetext{
${ }^{1} 3 \mathrm{~B}$ 's Research Group-Biomaterials, Biodegradables and Biomimetics, Department of Polymer Engineering, University of Minho, Headquarters of the European Institute of Excellence on Tissue Engineering and Regenerative Medicine, Guimarães, Portugal.

${ }^{2}$ Portuguese Associated Laboratory, Institute for Biotechnology and Bioengineering, Braga, Portugal.

${ }^{3}$ Institute for Science and Technology in Medicine, Keele University Medical School, Stoke-on-Trent, United Kingdom.
} 
An ideal bioreactor should enable controlled biochemical and/or biological processes. ${ }^{17,18}$ Recently, a rotating-wall vessel was developed by NASA aiming to protect cell cultures from the high shear forces generated during launch and landing of the space transport. ${ }^{19-21}$ This approach allows cell constructs to rotate in the vessels with minimal disruptive shears, thus simulating microgravity conditions. ${ }^{22,23}$ It has been shown that cells cultured within this bioreactor tend to aggregate and form structures resembling tissues. ${ }^{19}$ Studies on the effects of microgravity in the culture of osteoblast-like cells have been performed. However, conflicting results may be found in the literature. Some authors reported that microgravity influences the behavior of osteoblasts negatively by decreasing their viability. ${ }^{24-26}$ Other authors found that microgravity conditions do not influence the viability of osteoblasts even after several days of culture. ${ }^{27}$ It is not clear, however, if cell viability is only dependent on the culture conditions or may be related to the properties of the structures that support cell growth and proliferation. In this sense, we tested the hypothesis that the positive outcomes of the rotating bioreactor could be maximized using an optimized substrate for cell support during culture. To achieve this goal, BCP-NM constructs were used. To our best knowledge, this is the first report about the influence of dynamic culture conditions on BCP-NM constructs. It is herein shown that dynamic culture using the rotating bioreactor is more efficient to induce the formation of ECM on both PCL-NM and BCP-NM constructs. BCP-NM constructs appeared to facilitate cell adhesion in the first week of dynamic culture when compared with PCL-NM. In addition, BCP-NM constructs cultured under dynamic conditions for 14 days produced the highest amounts of the proteins related to the production of ECM, such as type I collagen and osteopontin, when compared with uncoated meshes, showing a clear effect of the microenvironment over the cell activity.

\section{Materials and Methods}

\section{Scaffolds}

Preparation of electrospun nanofibre meshes. PCL (Grade 787; Union Carbide, Danbury, CT) having a molecular weight of $125 \mathrm{KDa}$ was dissolved in chloroform (Aldrich, Steinheim, Germany)/dimethylformamide (Aldrich) in a ratio of 70:30. The obtained polymer solution was placed into a $5 \mathrm{~mL}$ syringe, with a metallic needle having an internal diameter of $0.8 \mathrm{~mm}$ attached to it. The syringe was connected to a syringe pump (KDS100; KD Scientific, Holliston, MA) to control the flow rate of the solution. A positive electrode was put in contact with the needle. Flat aluminum sheet covering the ground plate was used as the collector. A high-voltage power supply was employed to generate the electrostatic field $(0-25 \mathrm{kV})$. The capillary tip-tocollector distance and the flow rate were optimized, and the best conditions were obtained at $15 \mathrm{~cm}$ and $1 \mathrm{~mL} / \mathrm{h}$, respectively. The applied voltage was also optimized at $9 \mathrm{kV}$.

Biomimetic coating of the PCL-NMs. The biomimetic coating was performed as described elsewhere. ${ }^{8}$ In short, PCL-NMs were cut into square shapes $(10 \times 10 \mathrm{~mm})$ and immersed in a $0.5 \mathrm{M} \mathrm{NaOH}$ (Sigma, Deisenhofen, Germany) solution, at $37^{\circ} \mathrm{C}$, and stirred at $70 \mathrm{rpm}$ for $12 \mathrm{~h}$. Specimens were washed five times with ultrapure water and dried at $37^{\circ} \mathrm{C}$ for at least $5 \mathrm{~h}$.

The $\mathrm{NaOH}$-treated specimens were dipped in $0.1 \mathrm{M}$ $\mathrm{CaCl}_{2}$ (Merck, Darmstadt, Germany), at $37^{\circ} \mathrm{C}$ with agitation at $70 \mathrm{rpm}$ for $24 \mathrm{~h}$. After removal from the calcium solution, the specimens were rapidly dipped in $10 \mathrm{~mL}$ of ultrapure water, immediately dipped in $10 \mathrm{~mL}$ of $0.1 \mathrm{M}$ $\mathrm{K}_{2} \mathrm{HPO}_{4} \cdot 3 \mathrm{H}_{2} \mathrm{O}$ (Merck) for $15 \mathrm{~min}$, and immersed again in more $10 \mathrm{~mL}$ of ultrapure water for few seconds. Next, specimens were dipped in $10 \mathrm{~mL}$ of $1.5 \times$ simulated body fluid (SBF) for 4 days. The ion concentration $\left(\mathrm{Na}^{+} 243, \mathrm{~K}^{+} 7.5, \mathrm{Ca}^{2+}\right.$ 3.8, $\mathrm{Mg}^{2+}$ 2.6, $\left.\mathrm{Cl}^{-} 223, \mathrm{HCO}_{3}^{-} 6.3, \mathrm{HPO}_{4}^{2-} 1.5, \mathrm{SO}_{4}^{2-} 0.8 \mathrm{mM}\right)$ of the $1.5 \times$ SBF solution was approximately $1.5 \times$ higher than those present in the human blood plasma. The 1.5 $\times$ SBF was prepared by dissolving $\mathrm{NaCl}$ (Panreac, Barcelona, Spain), $\mathrm{NaHCO}_{3}$ (Merck), $\mathrm{KCl}$ (Panreac), $\mathrm{K}_{2} \mathrm{HPO}_{4} \cdot 3 \mathrm{H}_{2} \mathrm{O}$ (Merck), $\mathrm{MgCl}_{2} \cdot 6 \mathrm{H}_{2} \mathrm{O}$ (Aldrich), $\mathrm{CaCl}_{2}$ (Merck), and $\mathrm{Na}_{2} \mathrm{SO}_{4}$ (Panreac) in ultrapure water. The solution was buffered at $\mathrm{pH} 7.4$ with tris(hydroxymethyl)amino-methane (Aldrich) and $1 \mathrm{M} \mathrm{HCl}$ (Panreac) at $37^{\circ} \mathrm{C}$.

\section{Biological studies}

Bioreactor. A rotating bioreactor (Cellon, Strassen, Luxembourg) was used to culture constructs containing MG63 (ATCC CRL-1427; ATCC, Rockville, MD) osteoblast-like cells, ${ }^{28}$ originally isolated from a human osteosarcoma. The samples were placed in a disposable vessel containing $50 \mathrm{~mL}$ media. For gaseous exchange, the vessel was provided with a permeable membrane. The rotating speed of the bioreactor was kept as $16 \mathrm{rpm}$, these conditions being selected to avoid the collision of the constructs with the bioreactor walls and to facilitate mass transfer.

Cell seeding and bioreactor cultivation of tissueengineered constructs. Cells were cultured in Dulbecco's modified Eagle's medium (Sigma-Aldrich, Deisenhofen, Germany) supplemented with $10 \%$ heat-inactivated fetal bovine serum (Biochrom AG, Berlin, Germany) and 1\% antibiotic-antimycotic solution (Gibco, Paisley, United Kingdom). The cells were maintained in a humidified atmosphere with $5 \% \mathrm{CO}_{2}$ at $37^{\circ} \mathrm{C}$, with medium replaced every 2 days. BCPNM and PCL-NM samples were placed in 24-well plates and seeded by adding $1.5 \times 10^{5}$ cells $/ \mathrm{cm}^{2}$. The resulting constructs were put in a humidified incubator, at $37^{\circ} \mathrm{C}$, for a period of $6 \mathrm{~h}$. Afterward, part of the constructs was placed into the rotating bioreactor containing $50 \mathrm{~mL}$ complete medium. Two test groups were established: group 1-constructs were placed into the bioreactor for 7 days, immediately after seeding; group 2-after being cultured under static conditions for 7 days, constructs were placed into the bioreactor for 7 days more, for total of 14 days. In this particular case, those constructs were labeled as $14 \mathrm{~d}^{*}$. The remaining BCP-NM and PCL-NM constructs were incubated statically, after adding up $2 \mathrm{~mL}$ of media to each well, and used as control.

Morphological characterization of cultured cells. Adhesion, spreading, and morphology of osteoblast-like cells seeded on PCL-NM or BCP-NM were assessed by scanning electron microscopy (SEM) analysis using a Hitachi S4500 microscope (Hitachi Instruments, San Jose, CA). Before the 


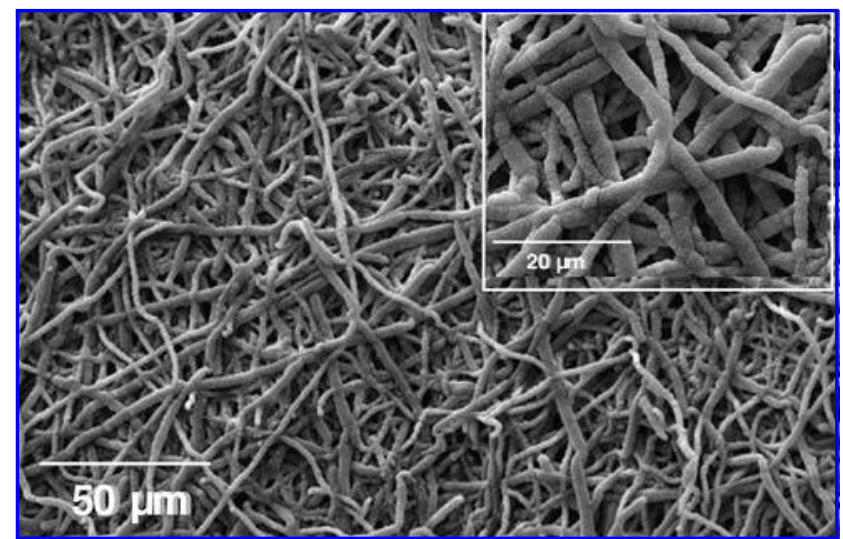

FIG. 1. Poly(caprolactone) nanofibre meshes (PCL-NMs) coated with a biomimetic calcium phosphate layer.

SEM analysis, samples were fixed with $2.5 \%$ glutaraldehyde, dehydrated with increasing concentrations of ethanol, and finally with hexamethyldisilazane (Sigma, Steinheim, Germany). Live and dead assays using a viability/ cytotoxicity kit (Invitrogen, Cergy Pontoise, France) for mammalian cells were used to assess the viability of the cells. In short, samples were removed from the incubator, placed in a 24-well microplate, and washed with $2 \mathrm{~mL}$ phosphatebuffered saline (PBS) each. Next, $500 \mu \mathrm{L}$ live/dead stain was added to each sample. Afterward, the microplate was covered by an aluminum foil and the samples incubated for 30-45 min at room temperature, previous to confocal microscopy analysis using an Olympus Fluoview FV300 confocal laser scanning microscope.

Cell viability and proliferation assays. Constructs were transferred into 24-well plates. The samples were washed twice with sterile PBS solution and transferred to Eppendorfs. Next, $450 \mu \mathrm{L}$ of Triton-X buffer containing $50 \mathrm{mM}$ Tris- $\mathrm{HCl}$ (Sigma), $0.9 \% \mathrm{NaCl}$ (Sigma), and $0.1 \%$ Triton- $\mathrm{X}$
(Sigma-Aldrich) were added to each Eppendorf. Extracts of the Triton-X buffer solution in contact with the samples were used for the quantification of total protein and DNA content. DNA was quantified via the picoGreen dsDNA quantitation assay (Invitrogen, Paisley, UK).

Total protein was measured using the Bio-Rad protein assay, and the samples were read at $460 \mathrm{~nm}$. The samples of PCL-NM and BCP-NM without any cells were used as control: those samples showed no measurable traces of protein.

Reverse transcriptase-polymerase chain reaction. Constructs were washed twice with PBS and samples were placed into Eppendorfs. Trizol $(800 \mu \mathrm{L})$ was added to each Eppendorf and vigorously mixed during $10 \mathrm{~s}$. Next, $200 \mu \mathrm{L}$ of chloroform was added and the tube incubated on ice for $15 \mathrm{~min}$. Samples were centrifuged at $10,000 \mathrm{rpm}$ for $15 \mathrm{~min}$ at $4{ }^{\circ} \mathrm{C}$ and the supernatants removed into clean, prechilled tubes. Five hundred microliters of ice-cold isopropanol was added to each tube and samples incubated at $-20^{\circ} \mathrm{C}$ overnight. The pellets were obtained by centrifugation at $10,000 \mathrm{rpm}$ for $15 \mathrm{~min}$ at $4{ }^{\circ} \mathrm{C}$ and washed with $70 \%$ ethanol. Each pellet was dissolved in $15 \mu \mathrm{L}$ of RNase-free water and kept at $-80^{\circ} \mathrm{C}$ to be used until use. Total RNAs were reverse transcribed to produce cDNA using the superscript II RNase $\mathrm{H}^{-}$reverse transcriptase kit (Invitrogen), according to the protocol of the manufacturer. The real-time polymerase chain reaction (PCR) for the gene expression of type I collagen, osteopontin, runx2, and 18s was performed using primers purchased from Applied Biosystem (Warrington, United Kingdom). The method used to calculate gene expression was one of the Delta-delta $\mathrm{Ct}$ method. In all cases the housekeeping gene used to calculate the Delta $\mathrm{Ct}$ was 18s; while the results obtained for PCL-NM samples have been used to normalize the data and to calculate the Delta-delta Ct.

Statistical analysis. Statistical data including average and standard deviations were obtained from four samples of
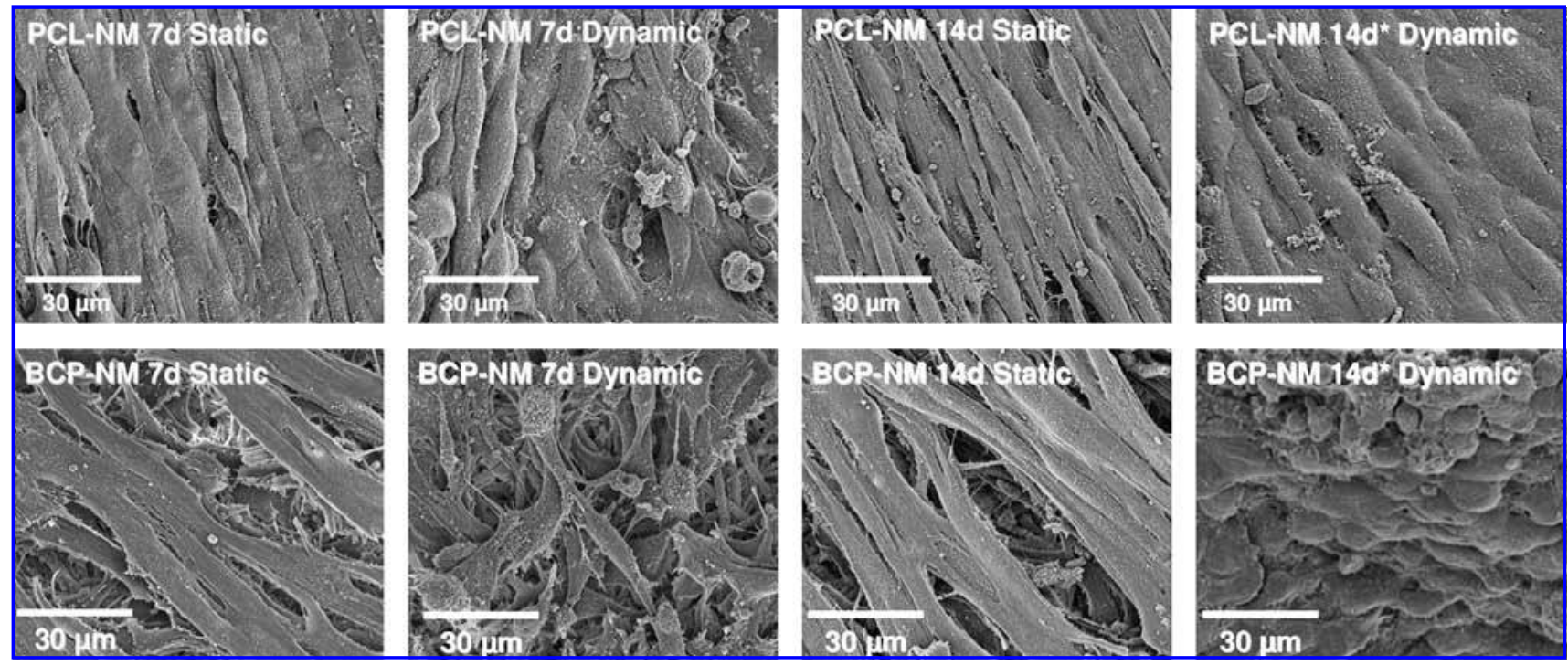

FIG. 2. Scanning electron micrographs showing the morphology of MG63 cells cultured on BCP-NM and PCL-NM under different conditions for different time periods. 

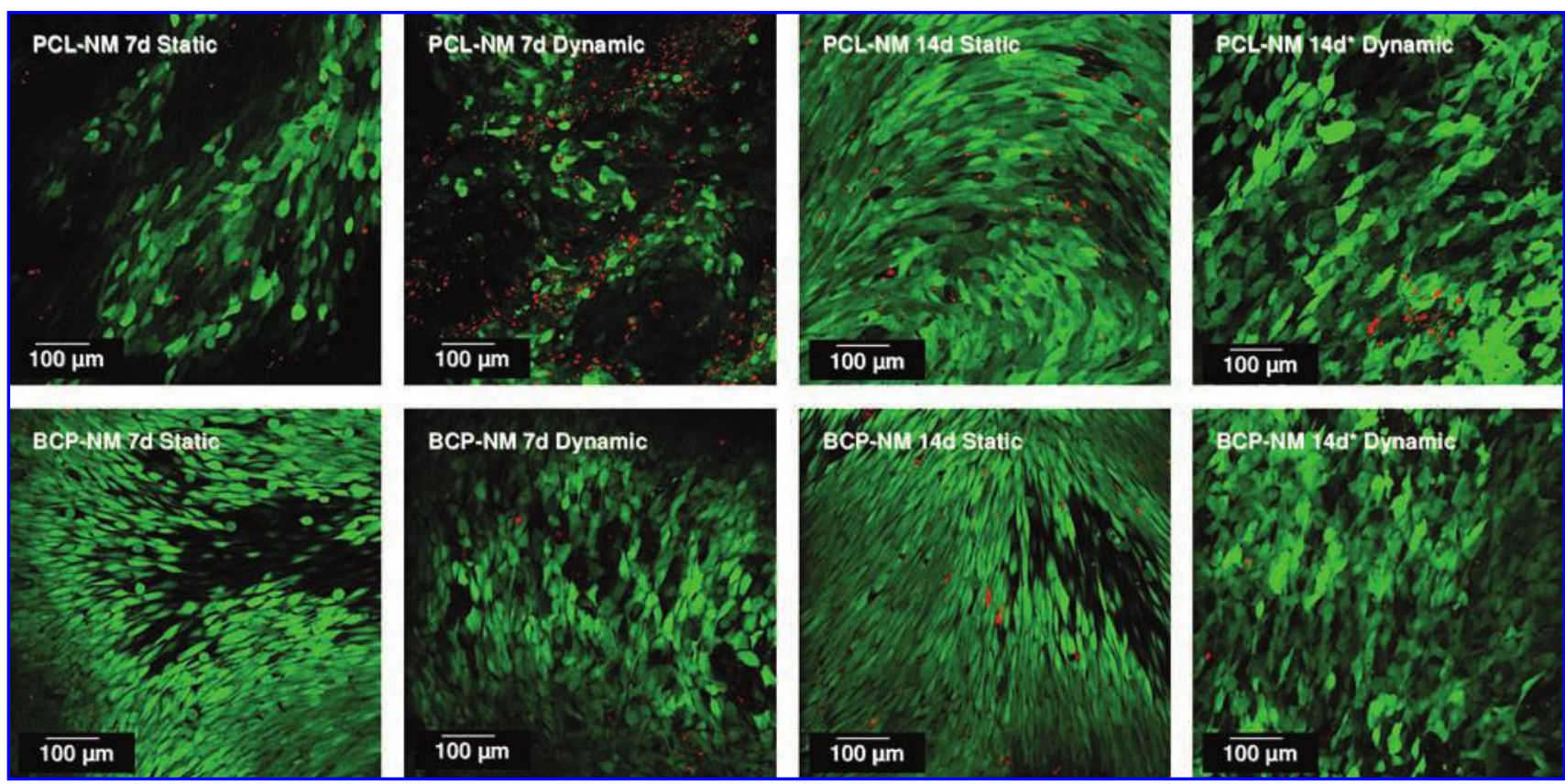

FIG. 3. Confocal fluorescence images of BCP-NM and PCL-NM constructs cultured under either static or dynamic conditions for different time periods. Green indicates live cells and red indicates dead cells.Color images available online at www.liebertonline.com/ten.

each experiment of biochemical assays (each experiment was repeated at least three times). Two-way analysis of variance was performed using GraphPad Prism version 5.00 for Windows (GraphPad Software, San Diego, CA).

\section{Results}

As it can be observed in Figure 1, biomimetic procedure was efficient to promote the homogeneous coating of the PCL-NM surfaces, while preserving the initial morphology, so that the high surface area of the meshes was maintained.

Obtained SEM (Fig. 2) and confocal fluorescence microscopy (Fig. 3) images revealed that, after 7 days, MG63 cells were able to attach to the surfaces of BCP-NM in both static and dynamic culture conditions. Nevertheless, differences in the morphology of the cells were observed. Cells cultured under conventional culture conditions developed an elongated fibroblast-like morphology. In contrast, under dynamic culture conditions, cells presented a round morphology. This difference in the morphology was more evident after 2 weeks.

Live/dead assays (Fig. 3) showed that PCL-NM constructs presented higher numbers of dead cells than BCP-NM. For example, highest numbers of dead cells were observed after 7 days in PCL-NM constructs cultured under dynamic conditions. After 2 weeks, the number of dead cells decreased in PCL-NM constructs, but was still higher than in coated constructs kept under similar conditions.

Although the number of dead cells was considerably higher in PCL-NM construct, no significant variation in the amount of DNA was observed between coated and noncoated constructs (Fig. 4). Both PCL-NM and BCP-NM cultured under static conditions presented a slight decrease in DNA content in the second week of incubation. On the other hand, the DNA content in the constructs cultured in the bioreactor was similar and almost constant for PCL-NM and $\mathrm{BCP}-\mathrm{NM}$ constructs during the whole culture period.

Overall, the total protein content normalized to the correspondent DNA amount was found to be higher in BCPNM constructs than in PCL-NM constructs when grown in the same culture conditions. In fact, significant differences $(p<0.001)$ were observed between coated and noncoated constructs cultured under dynamic conditions. The highest values were observed for BCP-NM constructs that were incubated for 14 days $\left(14 \mathrm{~d}^{*}\right)$ (Fig. 5) (7 days static +7 days dynamic).

After the second week of culture, mRNAs of type I collagen, runx2, and osteopontin were detected by reverse

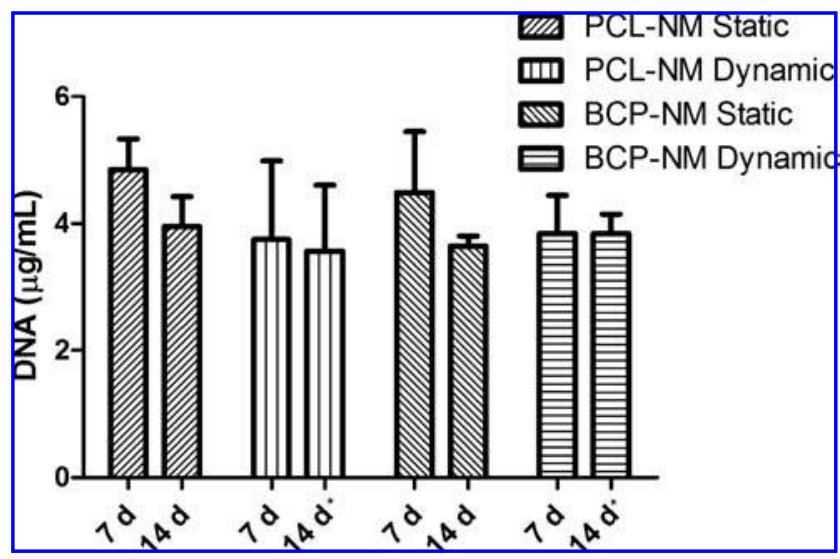

FIG. 4. DNA content of human osteoblast-like (MG63) cells growing either on BCP-NM or PCL-NM constructs under different culture conditions. 


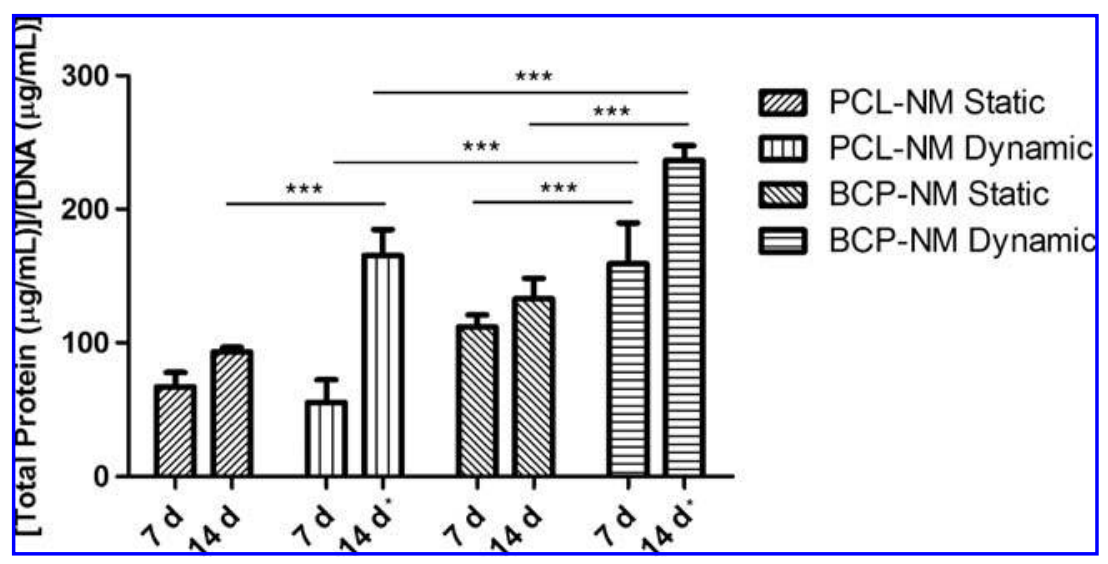

FIG. 5. Overall total protein contents normalized to the correspondent DNA amount for 7 and 14 days under different culture conditions. ${ }^{* * *} p<0.001$.

transcriptase-PCR. Results are presented in Figure 6 and indicate gene expression of osteopontin, runx2, and type I collagen on BCP-NM constructs cultured under either dynamic or static conditions, while the baseline represents the value above which the expression of BCP-NM construct is higher than the one of PCL-NM constructs. The expression levels of the ECM genes were higher for BCP-NM constructs cultured under dynamic conditions, where a remarkable overexpression was observed in the case of type I collagen gene.

\section{Discussion}

The importance of producing a new material to be used in tissue engineering mainly relies in an attempt to stimulate cells to proliferate and produce ECM, while regenerating the tissue. As it was shown previously, ${ }^{29,30}$ electrospun fibre meshes resemble the topographic features of ECM, which provides a more favorable microenvironment for the cells to regenerate the tissue, such as bone. In the current work, BCPNMs were used as a model that mimics the extracellular microenvironment found in bone. In this case a rotating-wall bioreactor was used to stimulate the diffusion of nutrients.

Coating nanofibre meshes with a biomimetic calcium phosphate layer was shown to improve cell attachment and proliferation. ${ }^{8}$ The mechanism involved in the formation of a BCP layer on the nanofibre meshes was already described. ${ }^{8}$ In short, the formation of an amorphous calcium phosphate layer originated during the surface modification step will produce a biomimetic calcium phosphate coating when in contact with a $1.5 \times \mathrm{SBF}$ solution. The coating composition is a carbonated apatite similar in composition to the inorganic phase of bone. 8,31

The differences in cell morphology between BCP-NM and PCL-NM constructs are probably related to the cell interactions with surfaces with different degrees of hydrophobicity or hydrophilicity. It is known that BCP-NM presents a much higher hydrophilicity than PCL-NM. ${ }^{8}$ The highest incidence of cell death on PCL-NM cultured in the rotating bioreactor for 7 days may be because of the difficulties for the cells to attach to a more hydrophobic surface under dynamic conditions. It was recently reported that the poor hydrophilicity of PCL-NM results in low cell-seeding efficiency and reduction in the ability of cell adhesion, migration, and proliferation in the initial step of culture. ${ }^{32}$ In the present work, such limitations seemed to be overcome when constructs were cultured for 7 days before the cultivation in dynamic conditions in the bioreactor. The culture conditions also affected the cell morphology. The more rounded morphology of the cells on constructs cultured under dynamic conditions may be related to a decrease in the disruptive shear forces within the rotating bioreactor because of the effects of microgravity. Contrary to previous studies which showed that microgravity conditions do not affect cell morphology, ${ }^{19}$ these findings show that in this particular case, cell morphology is affected by both the substrate and the culture conditions. For instance, a continuous randomization of the normal gravity vector subjects the cells to a state of simulated free fall that may have a strong influence in cell morphology.

Both BCP-NM and PCL-NM showed similar DNA levels. In fact, apart from the rise in the number of dead cells observed on PCL-NM constructs cultured under dynamic conditions, no significant differences were observed. This might support the evidence that dynamic culture environments provided by rotating bioreactors do not directly affect the cell viability. Moreover, it was possible to observe that similar cell numbers, as presented by the DNA content, produced significantly different quantities of total protein.

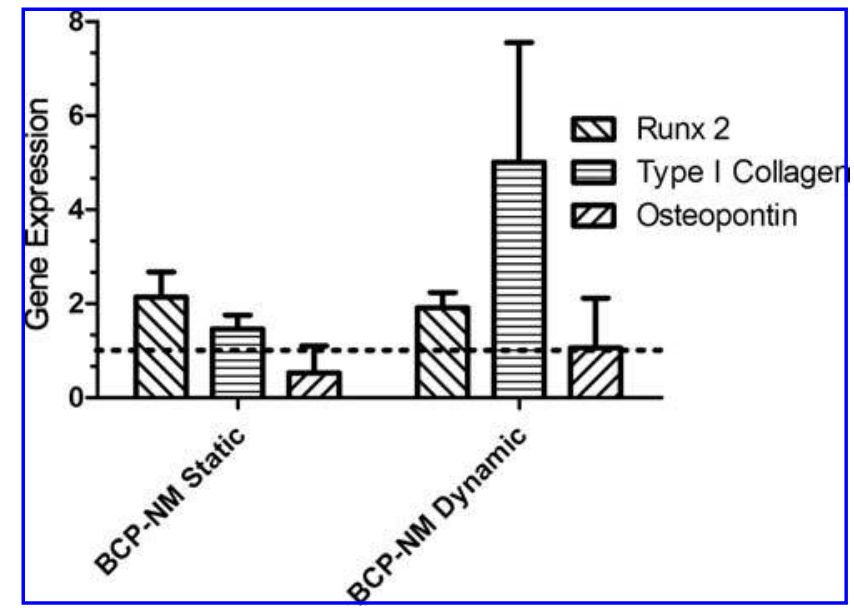

FIG. 6. Band densities for bone markers from MG63 cells at 14 days by real-time reverse transcriptase-polymerase chain reaction. In all cases the housekeeping gene used to calculate the Delta Ct was 18s, while the results obtained from PCLNM samples have been used to normalize the data and to calculate the Delta-delta Ct. Dotted line indicates baseline level $(=1)$ or unchanged gene expression level. 
Regarding BCP-NM constructs, it could be suggested that part of the proteins detected may be because of the adsorption of proteins from the culture medium by the calcium phosphate layer. However, PCL-NM and BCP-NM without cells, used as control, did not present any measurable trace of proteins (results not shown). This result shows that the total protein amount detected is mainly related to cell metabolism that, among other mechanisms, may produce anchoragerelated proteins for cell attachment. For instance, considering dynamic studies, the number of dead cells after 7 days of culture appeared to be higher on PCL-NM constructs, which presented significantly less protein than $\mathrm{BCP}-\mathrm{NM}$ constructs in the same time period. Although additional studies may be needed to clarify the mechanisms involved, it is clear that the conditions that lead to cell death also affect the production of total protein by the cells. Further studies may show if those two effects are causally correlated.

Increase in the btotal protein content is related to the production of ECM. In fact, reverse transcriptase-PCR analyses have shown that, besides the expression of runx2 (a transcription factor generally associated with osteoblast differentiation but which is also required for bone formation, being involved in the mineralization process ${ }^{33,34}$ ), osteogenic markers corresponding to type I collagen and ostepontin, extracellular structural proteins presented in bone, were also expressed. Not surprisingly, the higher expression of type I collagen, the most abundant protein in bone, was found on the constructs that presented the highest total protein production, that is, BCP-NM constructs cultured under dynamic conditions.

Current results confirm that BCP-NM present a better environment for cell attachment, growth, and spreading than PCL-NM. Combining BCP-NM constructs with dynamic culture conditions, which provided an efficient mass transfer, homogeneous cell distribution, and minimal damaging turbulence, enabled the production of a highly efficient model with potential applications in bone tissue engineering.

\section{Conclusions}

The results herein presented allow us to conclude that osteogenic cells can grow both on PCL-NM and BCP-NM. Dynamic culture in a rotating bioreactor for up to 14 days is associated with more osteogenic cell proliferation on BCPNM. Moreover, for cells cultured on BCP-NM under dynamic conditions, the production of total protein significantly increased. In addition, the higher expression of some extracellular structural proteins on BCP-NM constructs indicated a more favorable environment for the production of ECM. Further experiments should be performed to analyze the influence of the rotating bioreactors on the BCP-NM constructs for longer periods of time. However, we can conclude at this stage that, for the early stages of culture, the increase in mass transfer, combined with the appropriate substrate, appeared as a benefit for osteogenic cell growth and for the generation of ECM.

\section{Acknowledgments}

This work was developed under the scope of the EU Project Network of Excellence "Expertissues" (NMP3-CT2004-500283) and supported by Alea jacta est Marie Curie Actions (MEST-CT-2004-008104). M. Alves da Silva would like to acknowledge the Portuguese Foundation for Science and Technology for her grant (SFRH-BD-28708-2006). Jose V. Araujo is grateful to S. Rathbone, H. Sura, I. Wimpenny, I. Dublon, G. Jones, and E.D. Pinho for useful technical discussions.

\section{Disclosure Statement}

No competing financial interests exist.

\section{References}

1. Martins, A., Araujo, J.V., Reis, R.L., and Neves, N.M. Electrospun nanostructured scaffolds for tissue engineering applications. Nanomedicine 2, 929, 2007.

2. Ashammakhil, N., Ndreu, A., Piras, A.M., Nikkola, L., Sindelar, T., Ylikauppila, H., Harlin, A., Gomes, M.E., Neves, N.M., Chiellini, E., Chiellini, F., Hasirci, V., Redl, H., and Reis, R.L. Biodegradable nanomats produced by electrospinning: expanding multifunctionality and potential for tissue engineering. J Nanosci Nanotechnol 7, 862, 2007.

3. Burger, C., Hsiao, B.S., and Chu, B. Nanofibrous materials and their applications. Annu Rev Mater Res 36, 333, 2006.

4. Dorozhkin, S.V., and Epple, M. Biological and medical significance of calcium phosphates. Angewandte Chemie Int Ed 41, 3130, 2002.

5. Dubok, V.A. Bioceramics-yesterday, today, tomorrow. Powder Metallurgy Metal Ceram 39, 381, 2000.

6. Oliveira, A.L., Alves, C.M., and Reis, R.L. Cell adhesion and proliferation on biomimetic calcium-phosphate coatings produced by a sodium silicate gel methodology. J Mater Sci Mater Med 13, 1181, 2002.

7. Gomes, M.E., Azevedo, H.S., Moreira, A.R., Ella, V., Kellomaki, M., and Reis, R.L. Starch-poly(epsilon-caprolactone) and starch-poly(lactic acid) fibre-mesh scaffolds for bone tissue engineering applications: structure, mechanical properties and degradation behaviour. J Tissue Eng Regen Med 2, 243, 2008.

8. Araujo, J.V., Martins, A., Leonor, I.B., Pinho, E.D., Reis, R.L., and Neves, N.M. Surface controlled biomimetic coating of polycaprolactone nanofiber meshes to be used as bone extracellular matrix analogues. J Biomater Sci Polym Ed 19, 1261, 2008.

9. Araujo, J.V., Martins, A., Leonor, I.B., Pinho, E.D., Reis, R.L., and Neves, N.M. Surface controlled biomimetic coating of polycaprolactone nanofiber mesh architectures. Tissue Eng 13, 1759, 2007.

10. Martins, A., Pinho, E.D., Faria, S., Pashkuleva, I., Marques, A.P., Reis, R.L., and Neves, N.M. Surface modification of electrospun polycaprolactone nanofiber meshes by plasma treatment to enhance biological performance. Small 5, 1195, 2009.

11. Neves, N.M., Campos, R., Pedro, A., Cunha, J., Macedo, F., and Reis, R.L. Patterning of polymer nanofiber meshes by electrospinning for biomedical applications. Int J Nanomed 2, 1, 2007.

12. Martins, A., Chung, S., Pedro, A.J., Sousa, R.A., Marques, A.P., Reis, R.L., and Neves, N.M. Hierarchical starch-based fibrous scaffold for bone tissue engineering applications. J Tissue Eng Regen Med 3, 37, 2009.

13. Pinho, E.D., Martins, A., Araujo, J.V., Reis, R.L., and Neves, N.M. Degradable particulate composite reinforced with nanofibres for biomedical applications. Acta Biomater 5, 1104, 2009. 
14. Rolfe, P. Sensing in tissue bioreactors. Meas Sci Technol 17, $578,2006$.

15. Hughes, S., Dobson, J., and El Haj, A.J. Magnetic targeting of mechanosensors in bone cells for tissue engineering applications. J Biomech 40, S96, 2007.

16. Gomes, M.E., Sikavitsas, V.I., Behravesh, E., Reis, R.L., and Mikos, A.G. Effect of flow perfusion on the osteogenic differentiation of bone marrow stromal cells cultured on starchbased three-dimensional scaffolds. J Biomed Mater Res A 67, 87, 2003.

17. Martin, I., Wendt, D., and Heberer, M. The role of bioreactors in tissue engineering. Trends Biotechnol 22, 80, 2004.

18. Gomes, M.E., Bossano, C.M., Johnston, C.M., Reis, R.L., and Mikos, A.G. In vitro localization of bone growth factors in constructs of biodegradable scaffolds seeded with marrow stromal cells and cultured in a flow perfusion bioreactor. Tissue Eng 12, 177, 2006.

19. Granet, C., Laroche, N., Vico, L., Alexandre, C., and LafageProust, M.H. Rotating-wall vessels, promising bioreactors for osteoblastic cell culture: comparison with other 3D conditions. Med Biol Eng Comput 36, 513, 1998.

20. Freed, L.E., Pellis, N., Searby, N., de Luis, J., Preda, C., Bordonaro, J., and Vunjak-Novakovic, G. Microgravity cultivation of cells and tissues. Gravit Space Biol Bull 12, 57, 1999.

21. Pellis, N.R. Novel approaches to cellular transplantation from the U.S. Space Program. Diabetes Technol Ther 1, 85, 1999.

22. Duray, P.H., Hatfill, S.J., and Pellis, N.R. Tissue culture in microgravity. Sci Med (Phila) 4, 46, 1997.

23. Freed, L.E., Langer, R., Martin, I., Pellis, N.R., and VunjakNovakovic, G. Tissue engineering of cartilage in space. Proc Natl Acad Sci USA 94, 13885, 1997.

24. Sarkar, D., Nagaya, T., Koga, K., Kambe, F., Nomura, Y., and Seo, $\mathrm{H}$. Rotation in clinostat results in apoptosis of osteoblastic ROS 17/2.8 cells. J Gravit Physiol 7, P71, 2000.

25. Sarkar, D., Nagaya, T., Koga, K., Nomura, Y., Gruener, R., and Seo, H. Culture in vector-averaged gravity under clinostat rotation results in apoptosis of osteoblastic ROS 17/2.8 cells. J Bone Miner Res 15, 489, 2000.

26. Rucci, N., Migliaccio, S., Zani, B.M., Taranta, A., and Teti, A. Characterization of the osteoblast-like cell phenotype under microgravity conditions in the NASA-approved rotating wall vessel bioreactor (RWV). J Cell Biochem 85, 167, 2002.

27. Nakamura, H., Kumei, Y., Morita, S., Shimokawa, H., Ohya, K., and Shinomiya, K. Antagonism between apoptotic (Bax/Bcl-2) and anti-apoptotic (IAP) signals in human osteoblastic cells under vector-averaged gravity condition. Ann NY Acad Sci 1010, 143, 2003.
28. Billiau, A., Cassiman, J.J., Willems, D., and Verhelst, M. In vitro cultivation of human tumor tissues. Oncology 31, 257, 1975.

29. Pham, Q.P., Sharma, U., and Mikos, A.G. Electrospun poly(epsilon-caprolactone) microfiber and multilayer nanofiber/microfiber scaffolds: characterization of scaffolds and measurement of cellular infiltration. Biomacromolecules 7, 2796, 2006.

30. Li, W.J., Laurencin, C.T., Caterson, E.J., Tuan, R.S., and Ko, F.K. Electrospun nanofibrous structure: a novel scaffold for tissue engineering. J Biomed Mater Res 60, 613, 2002.

31. Ohtsuki, C., Kamitakahara, M., and Miyazaki, T. Coating bone-like apatite onto organic substrates using solutions mimicking body fluid. J Tissue Eng Regen Med 1, 33, 2007.

32. Kim, C.H., Khil, M.S., Kim, H.Y., Lee, H.U., and Jahng, K.Y. An improved hydrophilicity via electrospinning for enhanced cell attachment and proliferation. J Biomed Mater Res B Appl Biomater 78B, 283, 2006.

33. Otto, F., Thornell, A.P., Crompton, T., Denzel, A., Gilmour, K.C., Rosewell, I.R., Stamp, G.W.H., Beddington, R.S.P., Mundlos, S., Olsen, B.R., Selby, P.B., and Owen, M.J. Cbfa1, a candidate gene for cleidocranial dysplasia syndrome, is essential for osteoblast differentiation and bone development. Cell 89, 765, 1997.

34. Komori, T., Yagi, H., Nomura, S., Yamaguchi, A., Sasaki, K., Deguchi, K., Shimizu, Y., Bronson, R.T., Gao, Y.H., Inada, M., Sato, M., Okamoto, R., Kitamura, Y., Yoshiki, S., and Kishimoto, T. Targeted disruption of Cbfa1 results in a complete lack of bone formation owing to maturational arrest of osteoblasts. Cell 89, 755, 1997.

Address correspondence to: Nuno M. Neves, Ph.D.

3B's Research Group-Biomaterials, Biodegradables and Biomimetics

Department of Polymer Engineering University of Minho

Headquarters of the European Institute of Excellence on Tissue Engineering and Regenerative Medicine AvePark, Zona Industrial da Gandra Caldas das Taipas, 4806-909 Guimarães Portugal

E-mail: nuno@dep.uminho.pt

Received: April 3, 2009

Accepted: September 2, 2009

Online Publication Date: October 30, 2009 

This article has been cited by:

1. Kamlesh Shroff, Emilie L. Rexeisen, Manickam Adhimoolam Arunagirinathan, Efrosini Kokkoli. 2010. Fibronectin-mimetic peptide-amphiphile nanofiber gels support increased cell adhesion and promote ECM production. Soft Matter 6:20, 5064. [CrossRef] 